\section{Absolute judgments of colors using natural color names*}

\author{
ALPHONSE CHAPANIS and CHARLES M. OVERBEY† \\ The Johns Hopkins University, Baltimore, Maryland 21218
}

Twenty Ss, 10 male and 10 female, were required to select from a list of 36 common color names the correct name for each of 36 Munsell colored chips. On their first trial, with no prior training and without even having seen the set of stimuli in advance, our Ss gave results that were as good as, or better than, previous Es have reported at the conclusion of much longer experiments. On the last trial (Trial 10) our Ss transmitted about 5.07 bits of information, corresponding to the perfect discrimination of more than 33 colors. These figures approach the upper limit possible with 36 colors $(5.17$ bits). Reasons are given to suggest that the so-called human "channel capacity" to tasks of this kind could be even greater than we found here.

In classical psychophysics, an E presents a $S$ with two stimuli, a standard and a test stimulus, under conditions in which the comparison between them can be made easily. The stimuli may be for any sense modality and along any dimension or combination of dimensions. They may, for example, be different colors, intensities of sound, concentrations of salt, or sizes of disk. The $S$ is usually required to say only whether the two stimuli are the same or different. In the typical absolute judgment experiment, on the other hand, a $\mathrm{S}$ is presented with a single stimulus under generally contextless conditions and is asked to attach a veibal label, a name or a number, to the stimulus. The verbal label is often an artificial one, having no prior or obvious association with the stimulus.

A substantial body of information has now been accumulated to show that there is a dramatic shrinkage in the number of discriminable stimuli when one goes from comparative judgments to absolute judgments. For example, although the normal observer can make some 150 jnd discriminations of wavelength along the visible spectrum, he can reliably attach names, or numbers, to no more than 12 or 13 spectrum colors when he sees them one at a time. Such findings have led many investigators to postulate an apparent "channel capacity," or upper limit, for human "information processing."

That point of view, and the evidence for it, has been ably summarized by Miller in

* The work reported in this article was done under Contract Nonr-4010(03) between the Office of Naval Research and The Johns Hopkins University. This is Report No. 23 under that contract. Reproduction in whole or in part is permitted for any purpose of the United States Government.

†The work reported in this article was done while the second author was a National Science Foundation Predoctoral Fellow at The Johns Hopkins University. his article, "The Magical Number Seven, Plus or Minus Two [1956]." On the basis of many different experimental findings, Miller concluded that the human channel capacity for this kind of task seems to be below three bits for unidimensional stimuli and somewhat above three bits for multidimensional stimuli. In other words, all the available evidence seemed to show that people can reliably sort stimuli into only about seven different categories. This upper value appeared to be independent of the number of stimuli that were judged, their range, or the number of responses permitted. There were, however, some significant differences among the various stimulus dimensions. In general, people could make more correct absolute judgments for colors than for many other kinds of stimulus, for example, brightnesses of spots of light, sizes of visual stimuli, intensities of sound, frequencies of sound, and concentrations of liquid solutions.

The principal experiments that have been done with colors are those reported by Chapanis and Halsey (1956), Conover (1959), Halsey and Chapanis (1951), and Kintz, Parker, and Boynton (1969). Halsey and Chapanis (and Chapanis and Halsey) used spectrum colors equated for brightness and reported a maximum information transmitted of 3.66 bits, corresponding roughly to the perfect discrimination of 13 different stimuli. Conover used surface colors selected from the Munsell 50-hue maximum saturation series. His Ss were able to discriminate only about 9 different colors, corresponding to about 3.18 bits of information transmitted. The studies by Kintz et al were also done with spectrum colors equated for brightness. They found a maximum of 2.6 bits of transmitted information, corresponding to about 7 absolutely discriminable colors.

The experiment we report here differs from these earlier ones in four important respects: in the way the color domain was sampled, in the method used to select the stimuli, in the labels that Ss were asked to attach to the stimuli, and in the amount of training Ss were given.

\section{THE WAY IN WHICH THE COLOR SPACE WAS SAMPLED}

The experiments by Chapanis and Halsey and by Kintz et al used color stimuli that varied in wavelength but were equated for brightness. Although these stimuli varied in a single physical dimension, they varied in at least two psychological dimensions. Spectrum colors that have been equated for brightness vary in both hue and saturation.

Conover's stimuli were even more complex since the Munsell maximum saturation chips trace out an irregular line on the outside boundary of the color solid and so vary in hue, saturation, and lightness. Conover's stimuli consisted of 25 different hues, having saturations (chromas in Munsell nomenclature) that varied from 6.3 (blue green) to 12.4 (yellow red), and lightnesses (values in Munsell nomenclature) that varied from 3.56 (blue) to 7.63 (yellow).

Perhaps the most important thing to point out about the stimuli used in these earlier experiments is that although they are not truly unidimensional, neither are they truly multidimensional. In each experiment the stimuli varied in two or more psychological dimensions, but used only selected combinations of points along these dimensions. The experiment we report here made use of stimuli that are truly multidimensional in the sense that they tried to sample all of color space in its three psychological dimensions of hue, saturation, and lightness.

THE METHOD USED TO SELECT THE STIMULI

In absolute-judgment experiments, the $\mathrm{E}$ typically tries to select stimuli that will be discriminated about equally well. In the past, this has been done with one of two scaling procedures. Chapanis and Halsey and Kintz et al used stimuli that were spaced an equal number of jnds apart. Conover spaced his stimuli according to their position on a scale of equal discriminability.

The stimuli used in our experiment were selected by a new spacing method based upon the results of a large empirical study by Chapanis (1965). Briefly, in that study each of 40 different Ss was asked to pick from a large array of color chips that one chip which, in his opinion, best exemplified a color name. The array consisted of the 1,226 chips in the Cabinet Edition of the Munsell Book of Colors plus 
133 special chips generally of higher saturation than are contained in that book. The color name was picked from a list of 233 color names taken mainly from the National Bureau of Standards dictionary of color terms (Kelly \& Judd, 1955). Every S was required to make a selection for all 233 color names.

The data of that study were summarized in a large confusion matrix (233 color names by 1,359 color chips). The cell entries of the matrix showed how frequently every color chip was picked for every color name. From this matrix, Chapanis determined the largest set of color names that satisfied a $90 \%$ criterion of uniqueness. ${ }^{1}$ This criterion insures that $90 \%$ or more of the selections of color chips made by all Ss to any pair of color names were unique to those color names. The largest set of color names that satisfied this criterion turned out to be 36 .

The net result of Chapanis's procedure is to define a set of stimuli for which selections seldom overlap. There are, however, 245,580 different sets of 36 color names that satisfy the criterion. The set used in this experiment was selected by Chapanis largely on the basis of the simplicity of most of the color names that appear in it.

\section{THE LABELS THAT Ss WERE ASKED TO ATTACH TO THE STIMULI}

Experiments on absolute judgments have often required people to assign numbers to stimuli. To do this, Ss have had to learn arbitrary and artificial numerical response codes. The general intent underlying this practice has been to get relatively "pure" judgments for much the same reasons that nonsense syllables are so often used in the study of memory.

Both the Chapanis-Halsey and Conover studies used numerical response codes. Kintz et al required their $S s$ to use a combination of numbers and color names for those trials with more than 12 response categories. For example, in one set of trials, the responses between blue and blue green were labeled $\mathrm{BG} 1, \mathrm{BG} 2, \mathrm{BG} 3$, $\mathrm{BG} 4$, or BG5. In another set of trials, the Ss had to use a somewhat different combination of numbers and color names.

In contrast to the arbitrary response codes used in all these earlier experiments, we have capitalized upon the richness and the familiarity of our normal color language by using a selected set of common color names in this experiment.

\section{THE AMOUNT OF TRAINING Ss WERE GIVEN}

According to some views, one goal of absolute judgment experiments is to tell us something about the nature of human "information processing." Another more applied goal of such experiments is to find a set of stimuli that can be used to code information reliably (see, for example, Morgan et al, 1963, pp.81-90). In either case, the $\mathrm{S}$ 's task should ideally require little or no training. In actual fact, the numerical response codes used in the past have usually required long practice periods prior to the experimental or test trials. Even then it is difficult to be sure that the codes were thoroughly learned. In both the Chapanis-Halsey and Conover experiments, Ss practiced for long periods prior to the experimental trials. Although Kintz et al do not mention how much prior training their Ss had, two of the authors served alternately as $S$ and E. It scems safe to assume, therefore, that both had some thing to do with the construction of the response code and that they were thoroughly familiar with its meaning and use.

The need for long familiarization sessions prior to the start of data collection can be attributed to the arbitrary response codes that have traditionally been used. The more natural the response code, the less practice Ss will need to use it. Thus, a unique feature of our experiment is that we began collecting data with the very first color chip the $S$ saw.

\section{METHOD \\ Subjects \\ The Ss were 10 male and 10 female} undergraduates at Towson State College in Towson, Maryland. Their ages ranged from 18 to 24 years and all spoke English as their native tongue. All had normal color vision, as measured by both the Tokyo Medical College Color Vision Test (first edition) and the American Optical Company H-R-R Pseudoisochromatic Plates (second edition).

\section{Stimuli}

The set of 36 color stimuli chosen for this experiment appears in Table 1. Each stimulus is identified by its color name and by its corresponding Munsell specification. The color chips were Munsell Glossy Color File Swatches, $1-5 / 16 \times 1-5 / 8$ in. in size.

\section{Apparatus}

The apparatus used to present the stimuli had a vertical screen ( $18 \times 24$ in.) with a 1 -in.-sq aperture at its center. A horizontally mounted rotatable wheel behind the screen contained 36 upriglit blocks equally spaced around the periphery. Each of the blocks carried one of the stimulus chips. The location of the whecl permitted only one color at a time to be aligned with the aperture in the screen. The entire screen (except for the aperture) was covered by a neutral gray
Table 1

The 36 Color Names and the Munsell Specification of the Color Chip to Which Each Name Was Attached. Ss Were Given a List of the Color Names Only

\begin{tabular}{|c|c|c|c|}
\hline \multirow{2}{*}{$\frac{\text { Color Name }}{\text { Black }}$} & \multicolumn{2}{|c|}{ Munsell } & \multirow[t]{2}{*}{ Chip } \\
\hline & 1.0 & $\mathbf{N}$ & \\
\hline Dark Gray & 3.5 & $\mathbf{N}$ & \\
\hline Light Gray & 8.0 & $\mathbf{N}$ & \\
\hline White & 9.5 & $\mathbf{N}$ & \\
\hline Dark Red & 5.0 & $\mathbf{R}$ & $3 / 12$ \\
\hline Light Red & 5.0 & $\mathbf{R}$ & $6 / 12$ \\
\hline Reddish Gray & 5.0 & $\mathbf{R}$ & $5 / 4$ \\
\hline Pink & 10.0 & $\mathbf{R P}$ & $7 / 8$ \\
\hline Orange & 5.0 & YR & $7 / 14$ \\
\hline Orangish White & 5.0 & YR & $8 / 4$ \\
\hline Grayish Orange & 5.0 & $\mathbf{Y} \mathbf{R}$ & $6 / 8$ \\
\hline Brown & 7.5 & $\mathbf{Y R}$ & $3 / 6$ \\
\hline Brownish Gray & 7.5 & $\mathbf{Y R}$ & $5 / 2$ \\
\hline Yellow & 5.0 & $\mathbf{Y}$ & $8 / 12$ \\
\hline Grayish Yellow & 5.0 & $\mathbf{Y}$ & $8 / 6$ \\
\hline Yellowish Black & 5.0 & $\mathbf{Y}$ & $3 / 4$ \\
\hline Olive & 5.0 & GY & $4 / 6$ \\
\hline Green & 10.0 & $\mathbf{G Y}$ & $5 / 12$ \\
\hline Light Green & 10.0 & GY & $8 / 8$ \\
\hline Greenish Black & 2.5 & $\mathbf{G}$ & $3 / 4$ \\
\hline Greenish Gray & 10.0 & GY & $6 / 4$ \\
\hline Greenish White & 10.0 & GY & $9 / 2$ \\
\hline Light Bluish Green & 10.0 & BG & $7 / 6$ \\
\hline Dark Bluish Green & 10.0 & BG & $3 / 6$ \\
\hline Bluísh Green Gray & 10.0 & BG & $6 / 2$ \\
\hline Blue & 5.0 & PB & $4 / 12$ \\
\hline Bluish Black & 2.5 & PB & $2 / 4$ \\
\hline Bluish Gray & 2.5 & PB & $7 / 4$ \\
\hline Purplish Blue White & 10.0 & PB & $8 / 2$ \\
\hline Purple & 5.0 & $\mathbf{P}$ & $4 / 10$ \\
\hline Purplish Black & 5.0 & $\mathbf{P}$ & $2 / 4$ \\
\hline Grayish Purple & 5.0 & $\mathbf{P}$ & $5 / 4$ \\
\hline Purplish Red Gray & 7.5 & $\mathbf{R P}$ & $5 / 4$ \\
\hline Reddish Purple & 5.0 & $\mathbf{R P}$ & $4 / 10$ \\
\hline Reddish Purple Black & 5.0 & $\mathbf{R} \mathbf{P}$ & $2 / 6$ \\
\hline Purplish Pink White & 5.0 & $\mathbf{R P}$ & $8 / 4$ \\
\hline
\end{tabular}

sheet (Munsell N 6/). A two-position retractable shutter was mounted behind the screen so as to block the view through the apcrture between stimulus presentations. The shutter was covered in neutral gray to match the screen.

\section{Procedure}

The Ss were seated directly in front of the aperture in the screen and about 18 in. away from it. The illuminance (Standard liluminant $($ ) was measured before each experimental session and maintained at $24 \mathrm{fc}$.

The stimuli were presented one at a time in the aperture. Each $S$ was asked to choose, from a list of color names he kept before him (the 36 color names in Table 1 , but without their Munsell specifications), the name of each color chip he saw. Inmediately following a $S$ 's response, the shutter closed the aperture. The E recorded 


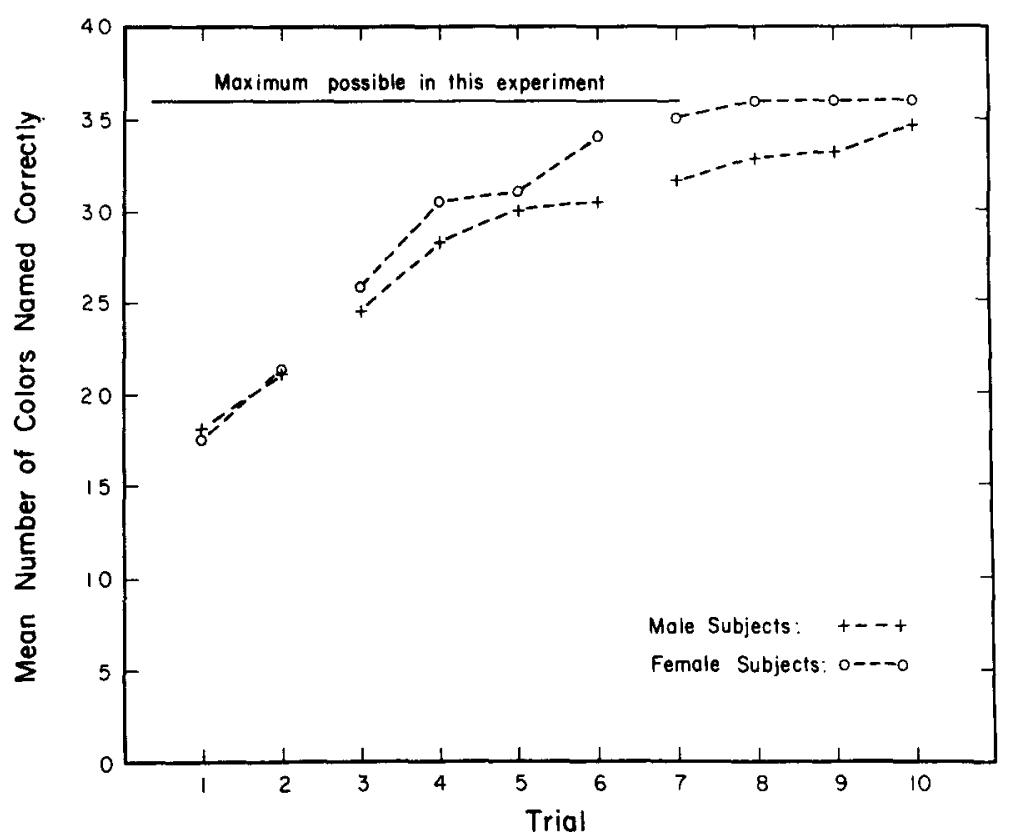

Fig. 1. Average numbers of colors identified correctly on the various trials. After Trial 2, the E started telling $S$ s about the correctness of each response. The data for Trials 7 through 10 involve the assumption that once a $S$ has gone through a complete error-free trial, he would continue to respond without error thereafter.

the S's last response and advanced the next color chip into alignment with the aperture. When both the $\mathrm{E}$ and the $\mathrm{S}$ were ready for the next judgment, the shutter was opened again.

A trial was completed when a $S$ had judged each of the 36 color chips once. No chip was presented twice in the same trial. Every $S$ saw on every trial a different random order of stimuli. The trials were self-paced, and no attempt was made to speed up either individual Ss or individual responses.

The Ss received no practice, nor did they see any of the color chips prior to the experimental sessions. Data were collected beginning with the first color chip presented on the first trial. On the first trial, Ss were naive about the set of stimuli and the context in which they were to make their judgments. Moreover, they received no information about the accuracy of their responses during the trial. The second trial was the same as the first except that by this time each $S$ had now seen the complete set of color chips. On the third and subsequent trials, Ss were told whether each judgment was right or wrong immediately after it was made. If the S's response was wrong, he was also told the correct answer. All trials for a given $\mathbf{S}$ were completed in a single experimental session. An experimental session ended when a $S$ correctly identified by color name all 36 color chips presented in a single trial.

The $\mathrm{Ss}$ were paid at the end of the per hour on these trials. On the third and experiment according to formulae that rewarded them for accuracy and for reaching criterion as quickly as possible. received 10 cents for each response on their first two trials. Since these trials averaged $19.7 \mathrm{~min}$ in duration, to respond without error thereafter. subsequent trials, Ss were paid according to a sliding scale that gave them less the more trials they took to reach criterion. Ss were told about the payment scheme before testing began.

\section{RESULTS}

Nineteen of the 20 Ss were able to reach the criterion of one complete error-free trial. The single exception was a male $\mathrm{S}$. Although this $S$ correctly named 33 color chips on his seventh trial, his comments to the $E$ during the next three trials indicated that he had lost interest in the experiment. At the end of about $3 \mathrm{~h}$ of testing, during which 10 trials had been completed, his session was terminated. The fastest Ss (6 of the 19) required only 6 trials to reach the criterion, while the slowest $S$ took 12 . All the female Ss reached the criterion within 8 trials. Since we stopped collecting data after a $S$ reached criterion, we have complete data on all Ss for only the first six trials. We have, however, assumed that once a $S$ went through a complete error-free trial he would continue to respond without error. This assumption enables us to compute some statistics for Trials 7 through 10 . We do not feel justified in making any estimates about performance beyond Trial 10 .

Figure 1 shows the average number of correct identifications for each trial for the male and female Ss separately. Since the means and variances of the data for the first six trials were negatively correlated, we tried a variety of standard

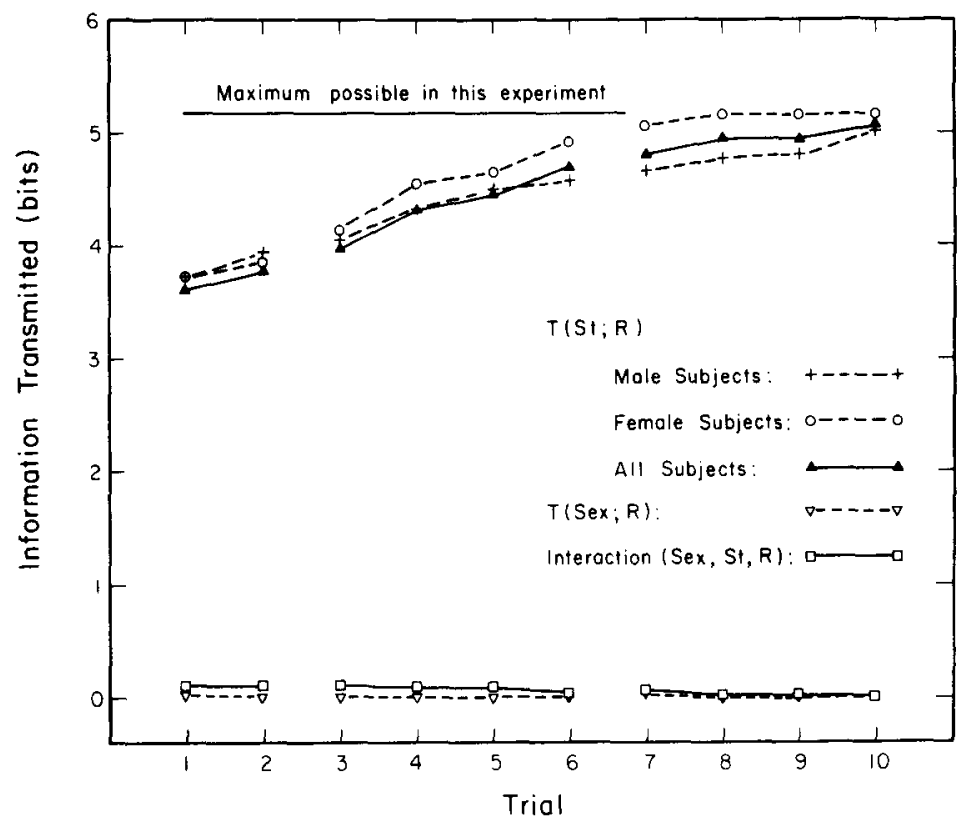

Fig. 2. Information transmitted on the various trials. After Trial 2, the E started telling Ss about the correctness of each response. The data for Trials 7 through 10 involve the assumption that once a $S$ has gone through a complete error-free trial, he would continue 
Table 2

The Number of Colors Correctly Identified by Various Numbers of Ss on Successive Trials

\begin{tabular}{|c|c|c|c|c|c|c|c|c|c|c|}
\hline \multirow{2}{*}{$\begin{array}{c}\text { Numbers } \\
\text { of Ss }\end{array}$} & \multicolumn{10}{|c|}{ Trial } \\
\hline & 1 & 2 & 3 & 4 & 5 & 6 & 7 & 8 & 9 & 10 \\
\hline 20 & 0 & 2 & 5 & 6 & 7 & 11 & 13 & 21 & 18 & 27 \\
\hline $18-19$ & 6 & 6 & 5 & 10 & 12 & 15 & 14 & 10 & 16 & 8 \\
\hline $16-17$ & 3 & 2 & 6 & 6 & 9 & 5 & 7 & 5 & 2 & 1 \\
\hline 14-15 & 4 & 5 & 7 & 8 & 3 & 2 & 1 & & & \\
\hline $12-13$ & 1 & 4 & 2 & 2 & 0 & 2 & 1 & & & \\
\hline $10-11$ & 3 & 2 & 5 & 3 & 4 & 1 & & & & \\
\hline $8-9$ & 2 & 7 & 3 & 1 & 1 & & & & & \\
\hline $6-7$ & 5 & 4 & 1 & & & & & & & \\
\hline 4-5 & 7 & 2 & 0 & & & & & & & \\
\hline $2-3$ & 4 & 1 & 2 & & & & & & & \\
\hline $0-1$ & 1 & 1 & & & & & & & & \\
\hline
\end{tabular}

transformations to reduce this proportionality. The one that reduced the correlations most nearly to zero is $\mathrm{X}^{\prime}=\mathrm{X} \sqrt{\mathrm{X}+0.5}$. An analysis of variance on the transformed data for the first six trials shows that trials differed significantly $[F(5,90)=112.89 ; p<0.001]$. The difference between the sexes was not significant $[F(1,18)=1.51 ; p>0.20]$. The interaction between sexes and trials was just barely significant $[\mathrm{F}(5,90)=2.30$; $0.06>p>0.05]$. The nature of this interaction is evident in Fig. 1. Although there is virtually no difference between the sexes on the first two trials, the female Ss do better than the male Ss on the third and subsequent trials.

The data have also been analyzed by multivariate information techniques (Garner, 1962). Figure 2 shows the amount of information transmitted in bits on each trial by the male Ss, the female Ss, and all Ss together. Figure 2 also shows the contribution of the interaction (A) and the amount of information transmitted from sexes to responses.

\section{DISCUSSION}

We believe the results of our study to be truly extraordinary. This experiment has yielded both a larger number of absolutely identifiable colors and a higher level of transmitted information than has been found in any previous study. On the very first trial, our Ss were able to identify more colors (an average of 18), and under more severe conditions (no prior context), than most investigators have obtained at the conclusion of much longer studies. For example, the maximum number of reliably discriminable colors previously reported after a long series of training trials was 13 (Halsey \& Chapanis, 1951). Even the poorest $S$ in this experiment correctly named 14 colors on his first trial, and seven of our $S$ s were able to make 20 to 24 correct judgments on that trial.

Since our first trial constifuted a far more severe challenge to our Ss than any of the tests made in experiments heretofore reported in the literature, the performance of our Ss on their second trial provides a fairer comparison with earlier findings. On that trial, Ss had at least seen the complete set of colors once and they had had an opportunity to become familiar with the experimental procedure. On the second trial, still without knowledge of results, the average number of correct responses increased to 21.2 . The poorest $S$ was able to name only 14 colors correctly; the best an impressive total of 31 .

Despite the gratifying results we obtained on the first two trials, further improvement occurred during successive trials, and Fig. 1 shows that it was very rapid. On their sixth trial, the female Ss were identifying an average of just over 34 colors correctly, while the male Ss were averaging 30.5 . On the 10 th trial, using the assumption stated earlier, every single one of the female Ss identified all 36 colors correctly, while the male Ss averaged 34.6 colors correct

Parallel outcomes appear when the data are analyzed by multivariate information techniques. On the first trial, for example, the total amount of information transmitted, 3.62 bits, compares favorably with the highest value, 3.66 bits, Chapanis and Halsey obtained after their Ss had received intensive training. The result of our first trial is substantially higher than the maximum value reported by either Conover ( 3.18 bits) or Kintz et al $(2.56$ bits) at the conclusion of their investigations.

Figure 2 shows the same kind of marked improvement on successive trials as is evident in Fig. 1. By the end of their sixth trial, our Ss were transmitting 4.70 bits of information, corresponding to the perfect discrimination of 26 colors. That number is three times as large as the maximum number of colors usually recommended (Conover, Morgan et al) as being reliably discriminable. Between the second and sixth trials, the female $S s$ in this experiment effectively doubled the number of response categorics that they could use reliably. On the 10th trial, the information transmitted from stimuli to responses for the female Ss was 5.17 bits (the maximum possible under the conditions of this experiment); for the male Ss, 5.01 bits; and for all Ss together, 5.07 bits.

As shown in Fig. 2, a slight amount of the total information transmitted for all Ss on the first three trials is due to the information transmitted from sexes to responses. From Trial 4 onward, however, the contribution from sexes to responses is practically nonexistent. The amount of information attributable to the interaction among stimuli, sexes, and responses was also extremely small on each trial. This means, in effect, that the two groups of Ss tended to use the color names in slightly different ways early in the experiment but that even these small differences disappeared in the later trials.

\section{Colors for Coding Purposes}

Although the measures reported so far are conventional and useful for purposes of basic research, practical applications of data such as these require far more stringent criteria of performance. If colors are to be used for coding purposes, they must be used correctly by all Ss. Average numbers of colors identified correctly, and measures of information transmitted, do not, of course, tell us which colors or how many colors, were identified correctly by all Ss. Table 2 contains frequency distributions of the numbers of colors that were used correctly by various numbers of Ss on the several trials. Looked at in this way, our data are not so impressive at first. On the first trial, not a single color was identified correctly by all $20 \mathrm{Ss}$. On the second trial, two colors were identified correctly by all $20 \mathrm{Ss}$; on the third trial, 5 ; and so on. On the 10th trial, 27 colors could presumably be identified correctly by all Ss. That number is, of course, far greater than the 7 discovered by Conover or the 13 reported by Chapanis and Halsey. Nonetheless, it is clear that even our select group of colors could not be put into practical use without a period of training, or familiarization, for the people who were to use them. Our data suggest, however, that such a training period need not be an extensive one.

\section{On the Maximum Number of Colors that} can be Identified Absolutely

Have we discovered the largest number of colors that can be identificd absolutely? Probably not. In the first place, the set of 36 colors we chose for this experiment was one of 245,580 different sets of 36 colors that satisfy the same criterion of overlapping (refer to a prior section for details). We have no assurance that this 
particular set of 36 color names is the one that would give the best performance in an absolute-judgment experiment. It is at least conceivable that some other set of 36 colors would have fared even better.

Second, the fact that our Ss were able to do so well with this set of colors suggests that these colors were selected too strictly. In the same analysis that led to this set of 36 colors (refer to a prior section and Note 1), Chapanis also used other criteria of uniqueness. With a $75 \%$ criterion of uniqueness, for example, he found that 53 was the largest number of nonoverlapping colors that could be extracted from his original set of 233 . There were, moreover, 763,200 different sets of 53 colors that satisfied that criterion. A $60 \%$ criterion of uniqueness yielded $5,160,960$ sets of 71 colors. These correspond to maximum information transmissions of 5.73 and 6.15 bits, respectively. Because of the success that we had with our set of 36 colors, it is at least possible that larger sets of colors would have yielded even higher rates of information transmitted.

Finally, our set of 36 stimuli are no better than the data from which they originally derive. Although Chapanis tried to sample all of color space in his 1965 study, he clearly did not succeed. Eighteen percent of his original sample of color chips were never selected by any $S$ in response to any of his 233 color names. This means that the 36 colors in this experiment did not sample all of color space, but, at best, only $82 \%$ of it. If we had been able to find a set of colors that covered color space more thoroughly, we should presumably be able to obtain an even larger number of absolutely identifiable colors, and higher rates of transmitted information, than those we report herc.

\section{On the Problem of Multidimensionality}

In his paper, Miller makes a great deal of the distinction between unidimensional and multidimensional stimuli. However appealing his argument appears at first glance, we believe that the issue is by no means as simple as Miller described it. In the first place, it is not entirely clear whether the distinction should apply to the physical dimensionality of the stimulus or to the psychological dimensionality of the percept. Although Miller clearly means the latter, other information theorists have not always been as consistent as he. Let us grant that we should be looking at psychological dimensions. Then how many dimensions did our stimuli have? Most people would agree that our stimuli varied in at least three psychological dimensions: hue, lightness, and saturation. But our stimuli also varied in the dimensions of insistence, pronouncedness, and warmth (see The Science of Color, 1953, especially Chap. 5). Moreover, recent experiments by Egeth and Pachella (1969) suggest that interdimensional interference is a significant problem in multidimensional stimuli. The full implications of these interference effects have not yet been determined. Although this is not the place to discuss the issue, we would like to argue that the psychological dimensionality of perceptual experience is by no means as simple as appears at first.

Miller hazarded in his Fig. 6 (p. 88) a relationship between channel capacity and the number of variable aspects of the stimuli that were being judged. If we accept for the moment that our stimuli are three-dimensional, then Miller's curve predicts for colors a maximum information transmission of about 4.40 bits. Our Ss exceeded this value on their fifth trial, and continued to increase even more after that. In fairness to Miller, however, we should emphasize that Miller drew his curve with hesitancy and with statements of caution about the limitations of the data on which he was basing his curve. In any case, we have at least added another datum point to Miller's figure, a point which in our opinion suggests that there should perhaps be different curves for different sense modalities.

\section{A Methodological Issue}

We believe that our findings raise some fundamental questions about the validity and methodology of absolute judgment experiments in general. Our exceptional results are due, in large measure, to the response code we used. When experiments of this kind are designed to determine the largest number of reliably discrininable categories into which people can sort stimuli, or the so-called human "channel capacity," then the response code should be overlearned, meaningful, and compatible with the stimuli. In their attempts to purify their procedures, Es who have worked on these problems in the past (and the senior author counts himself among that number) may have put artificially difficult constraints on their Ss. Given these constraints, there was really not much possibility that these Es could ever have discovered the true "channel capacity" of the human organism.

\section{REFERENCES}

CHAPANIS, A. Color names for color space. American Scientist, 1965, 53, 327-346.

CHAPANIS, A., \& HALSEY, R. M. Absolute judgments of spectrum colors. Joumal of Psychology, 1956, 42, 99-103.

COMMITTEE ON COLORIMETRY, OPTICAL SOCIETY OF AMERICA. The science of color. New York: Thomas Y. Crowell, 1953.

CONOVER, D. The amount of information in the absolute judgment of Munsell hues, WADC Technical Note 58-262. June 1959.

EGETH, H., \& PACHELLA, R. Multidimensional stimulus identification. Perception \& Psychophysics, 1969, 5, 341-346.

GARNER, W. R. Uncertainty and structure as psychological concepts. New York: Wiley, 1962.

HALSEY, R. M., \& CHAPANIS, A. On the number of absolutely identifiable spectral hues. Journal of the Optical Society of America, 1951, 41, 1057-1058.

KELLY, K. L., \& JUDD, D. B. The ISCC-NBS method of designating colors and a dictionary of color names. National Bureau of Standards Circular 553. Washington, D.C: U.S. Government Printing Office, 1955.

KINTZ, R. T., PARKER, J. A., \& BOYNTON, R. M. Information transmission in spectral color naming. Perception \& Psychophysics, 1969,5, 241-245.

MILLER, G. A. The magical number seven, plus or minus two: Some limits on our capacity for processing information. Psychological Review, $1956,63,81-97$

MORGAN, C. T., COOK, J. S., III, CHAPANIS A., \& LUND, M. W. Iuman engineering guide to equipment design. New York: McGraw-Hill. 1963.

\section{NOTE}

1. This analysis was done subsequent to Chapanis's 1965 study and has not yet been published.

(Accepted for publication September 14, 1970.) 